Proc. Indian Acad. Sci. (Earth Planet. Sci.), Vol. 94, No. 2, July 1985, pp. 147-157.

(C) Printed in India.

\title{
Interaction of monsoon with northern hemisphere mid-latitude circulation
}

\author{
S T AWADE, M Y TOTAGI and S M BAWISKAR \\ Indian Institute of Tropical Meteorology, Pune 411005 , India
}

MS received 24 November 1983; revised 17 April 1985

\begin{abstract}
Fourier analysis has been used for the monthly mean northern hemispheric geopotential height for the levels $700 \mathrm{mb}$ and $300 \mathrm{mb}$ for the months April through August in bad monsoon years (1972, 74 and 79) and in years of good monsoon rainfall over India (1967, $73,77)$. From the Fourier coefficients the transport of momentum and of sensible heat have been computed in wave number domain.

Waves 1 to 3 show contrasting features during years of good monsoon and bad monsoon. Northward transport of momentum across subtropical latitudes is larger in good monsoon years, while northward transport of sensible heat is larger in bad monsoon years. In good monsoon years there is a large divergence of momentum in the subtropics while there is a large convergence of momentum in the mid-latitudes. In bad monsoon years there is a large divergence of sensible heat in the sub-tropics, but a large convergence in the mid-latitudes. These quantities show similar features in pre-monsoon (April to May) during good and bad monsoon years.
\end{abstract}

Keywords. Fourier analysis; mid-latitude circulation; sensible heat; momentum transport.

\section{Introduction}

Indian summer monsoon is a component of the planetary scale monsoon during the northern hemispheric summer season, and planetary scale monsoon is brought about and maintained by the redistribution of heat sources and sinks in which the differential heating between continents and oceans plays a dominant role. The purpose of this paper is to study the effect of mid-latitude and extra tropical circulation on the activity of the monsoon. This has been qualitatively studied earlier by a few workers (Ramaswamy 1958, 1962; Pisharoty and Desai 1956; Pisharoty and Asnani 1958; Ramamurthy 1969; Raman and Rao 1981).

Here we have computed the transport of momentum and of sensible heat in the years of good and bad summer monsoon in India in order to understand the anomalies in the monsoon activity in terms of global circulation of the atmosphere.

\section{Data and method of analysis}

Monthly mean northern hemispheric geopotential height data for the levels $700 \mathrm{mb}$ and $300 \mathrm{mb}$ at $5^{\circ}$ lat/long intervals collected from hemispheric charts prepared by Free University of Berlin and Hydrometeorological service of USSR for the years 1967, 72, 73, 74, 77 and 79 for the months April through August have been subjected to Fourier analysis. 
We have followed the standard definition of good and bad monsoon years as practised by the India Meteorological Department. Of these 1967, 73 and 77 correspond to good monsoon conditions over India. The years 1972, 74 and 79 correspond to bad monsoon years. Monsoon performance in these years is given in table 1 .

Using Fourier analysis, we have for height, $z$

$$
z(\lambda)=\sum_{m=0}^{\infty}\left(a_{m}(\phi) \cos m \lambda+b_{m}(\phi) \sin m \lambda\right)
$$

The amplitude $R_{m}$ and phase $\varepsilon_{m}$ of the $m$ th wave are given by

$$
R_{m}=\left(a_{m}^{2}+b_{m}^{2}\right)^{1 / 2}, \varepsilon_{m}=(1 / m) \arctan \left(b_{m} / a_{m}\right)
$$

Using geostrophic approximation for winds, we obtain the flux of angular momentum across a latitude circle by standing eddies (Lorenz 1966; Awade 1979; Awade et al 1981) which is given by

$$
\left(2 \pi a^{2} \cos ^{2} \phi / g\right) \int_{p_{1}}^{p_{2}}\left[\bar{U}^{*} \bar{V}^{*}\right] \mathrm{d} p
$$

where,

$$
\begin{aligned}
{\left[\bar{U}^{*} \bar{V}^{*}\right] } & =-\left(g^{2} / 4 \Omega^{2} a^{2} \sin ^{2} \phi \cos \phi\right)\left[\frac{\partial \bar{z}^{*}}{\partial \lambda} \frac{\partial \bar{z}^{*}}{\partial \phi}\right] \\
& \approx\left(g^{2} / 4 \Omega^{2} a^{2} \sin ^{2} \phi \cos \phi\right) \sum_{m=1}^{16} \frac{1}{2} m^{2} R_{m}^{2} \frac{\partial \varepsilon_{m}}{\partial \phi}
\end{aligned}
$$

The flux of sensible heat across a latitude circle due to standing eddies is given by (Lorenz 1966),

$$
(2 \pi a \cos \phi / g) \int_{p_{1}}^{p_{2}} C_{p}\left[\bar{V}^{*} \bar{T}^{*}\right] \mathrm{d} p
$$

where,

$$
\begin{aligned}
{\left[\bar{V}^{*} \bar{T}^{*}\right] } & =-\left(g^{2} p / 2 \Omega a R \sin \phi \cos \phi\right)\left[\frac{\partial \bar{z}^{*}}{\partial \lambda} \frac{\partial \bar{z}^{*}}{\partial p}\right] \\
& \approx\left(g^{2} p / 2 \Omega a R \sin \phi \cos \phi\right) \sum_{m=1}^{16} \frac{1}{2} m^{2} R_{m}^{2} \frac{\partial \varepsilon_{m}}{\partial p}
\end{aligned}
$$

Here, the symbols []$, *$ and - indicate the average over a latitude circle, deviation from

Table 1. Monsoon performance

\begin{tabular}{lcccccc}
\hline Year & 1967 & 1972 & 1973 & 1974 & 1977 & 1979 \\
\hline $\begin{array}{l}\text { Percentage depar- } \\
\text { ture of rainfall from } \\
\text { normal (June- }\end{array}$ & -0.3 & -24.3 & 4.6 & -12.2 & 4.9 & -16.0 \\
\begin{tabular}{l} 
September) \\
\hline
\end{tabular} & & & & & & \\
\hline
\end{tabular}


average over latitude circle and monthly time average respectively. $\Omega$ stands for the angular velocity of the earth and $p_{1}$ and $p_{2}$ are pressures at upper and lower levels respectively. Other symbols have their usual meaning.

\section{Result and discussion}

\subsection{Transport of momentum}

The transport of momentum was computed using (3) at $700 \mathrm{mb}$ and $300 \mathrm{mb}$ levels during pre-monsoon months (April and May) and monsoon months (June through August), hereafter, these will be referred to as $\mathbf{A}-\mathbf{M}$ and $\mathbf{J}-\mathbf{A}$ respectively.

In order to understand the broad features, we obtained the transport due to standing eddies contributed by long waves (waves 1 to 4), medium waves (waves 5 to 10) and short waves (waves 11 to 16 ) across the latitudes $20^{\circ} \mathrm{N}$ to $60^{\circ} \mathrm{N}$. Table 2 gives the transport of momentum during A-M and J-A at $700 \mathrm{mb}$ level. There is no contrast in both the periods at $700 \mathrm{mb}$ level (table 2). Since the contrast is significant at $300 \mathrm{mb}$ level during $\mathbf{J}-\mathbf{A}$, we consider this level in some detail. Table 3 gives the transport of momentum and of sensible heat during $\mathrm{J}$-A contributed by long, medium and short waves and figure 1 shows the transport of momentum across $30^{\circ} \mathrm{N}$ at $300 \mathrm{mb}$ level in wave number domain.

The contribution of momentum flux at $300 \mathrm{mb}$ level during $\mathrm{J}$-A by long waves between latitudes $20^{\circ} \mathrm{N}$ and $30^{\circ} \mathrm{N}$ is northward (table 3) and it is maximum across $30^{\circ} \mathrm{N}$. It is larger in good monsoon years than in bad monsoon years at this latitude. At $60^{\circ} \mathrm{N}$, the transport is southward. However, it is small. There is significant northward contribution by medium waves between latitudes $30^{\circ} \mathrm{N}$ and $50^{\circ} \mathrm{N}$, but there is no contrast. The contribution by short waves is small. Long waves and indeed all waves show larger northward transport across $30^{\circ} \mathrm{N}$ in good monsoon years than in bad monsoon years.

Waves 1 and 3 are prominent across $30^{\circ} \mathrm{N}$ in all these years (figure 1). The transport by wave 3 across $30^{\circ} \mathrm{N}$ is larger and further northward in good monsoon years than in bad monsoon years. Wave 2 generally transports momentum southward. Waves 6 through 10 contribute to the northward transport in all these years.

\subsection{Meridional transport of sensible heat}

The transport of sensible heat computed across $20^{\circ} \mathrm{N}$ through $60^{\circ} \mathrm{N}$ using (6) at $500 \mathrm{mb}$ level during monsoon months (June through August) for waves 1 to 16 for all these years are also given in table 3. Figure 2 depicts the vertical tilt for waves 1 and 2 during July and figure 3 gives the transport across $30^{\circ} \mathrm{N}$ at $500 \mathrm{mb}$ level in the wave number domain. The transport of sensible heat during J-A by long waves across $20^{\circ} \mathrm{N}$ is southward in all these years (table 3). It is generally southward across $30^{\circ} \mathrm{N}$ in good monsoon and northward in bad monsoon. It is generally northward across $40^{\circ} \mathrm{N}$ (table 3) and variable across $50^{\circ} \mathrm{N}$. At $60^{\circ} \mathrm{N}$, the transport is northward. The transport due to medium waves is northward between latitudes $20^{\circ} \mathrm{N}$ and $60^{\circ} \mathrm{N}$. The contribution by medium waves is significant in regions between latitudes $30^{\circ} \mathrm{N}$ and $40^{\circ} \mathrm{N}$ but there is no 


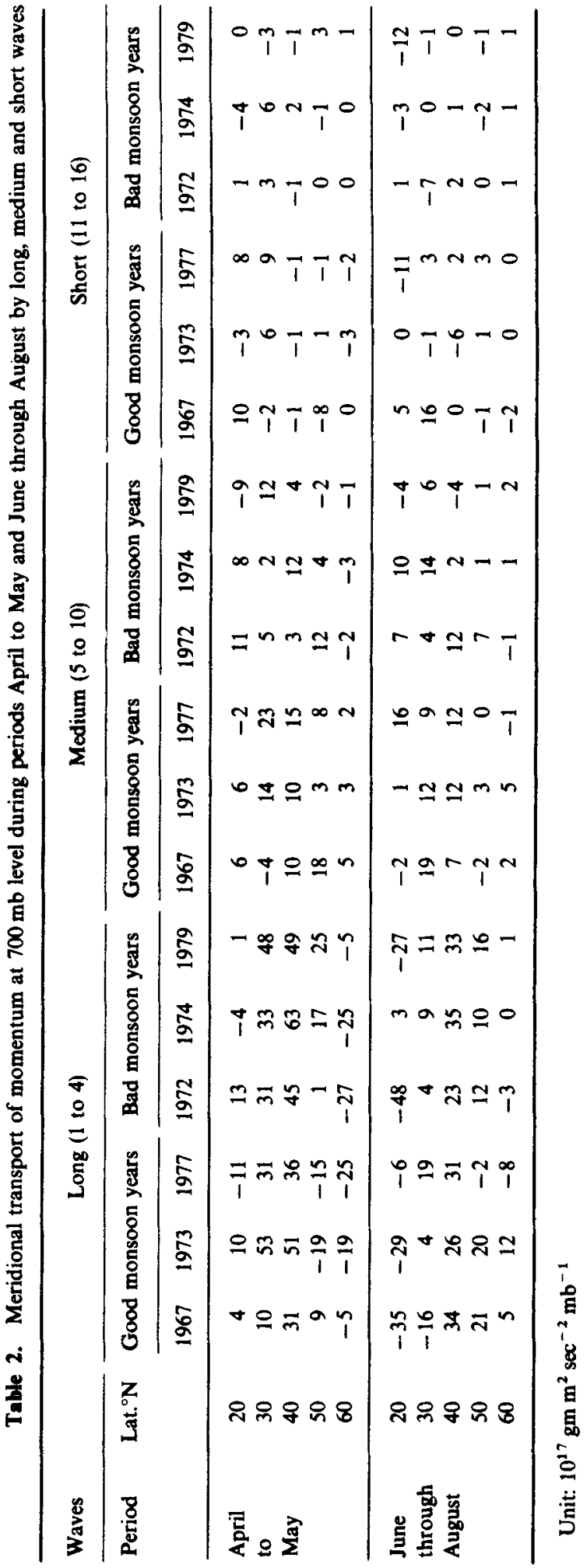




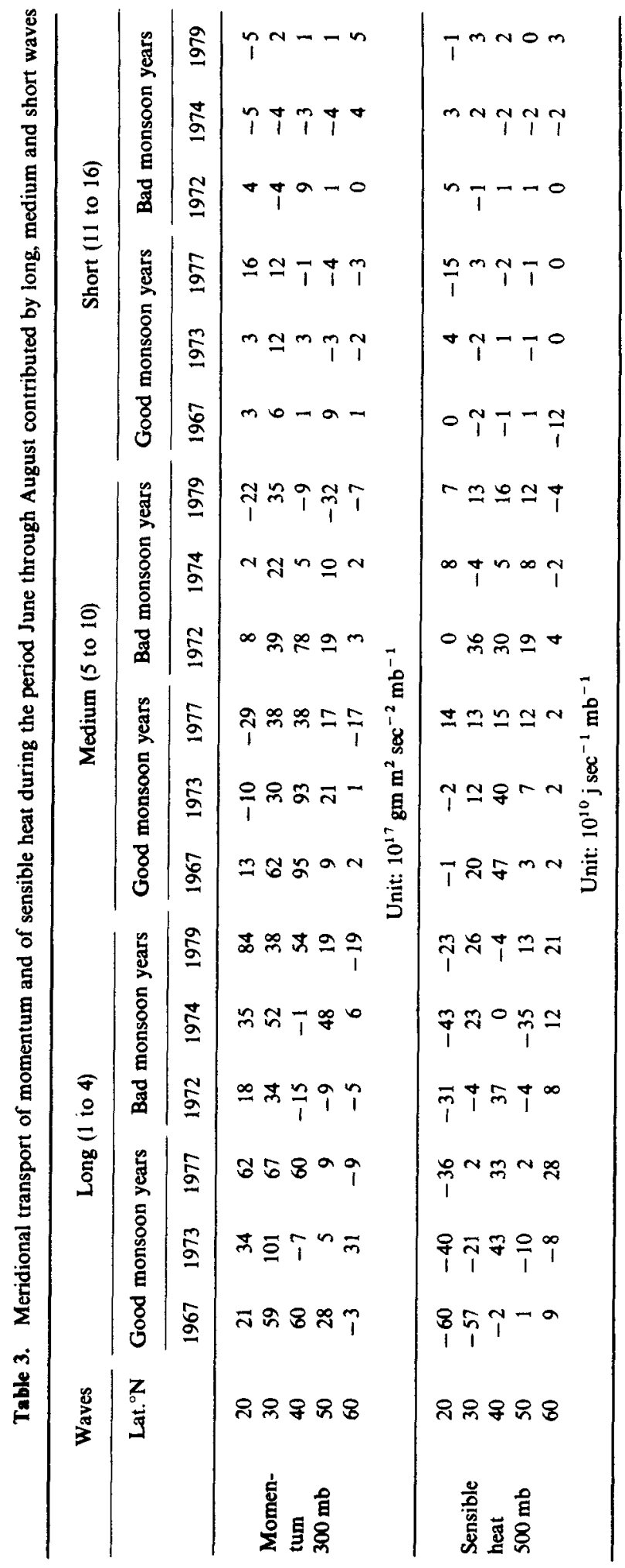




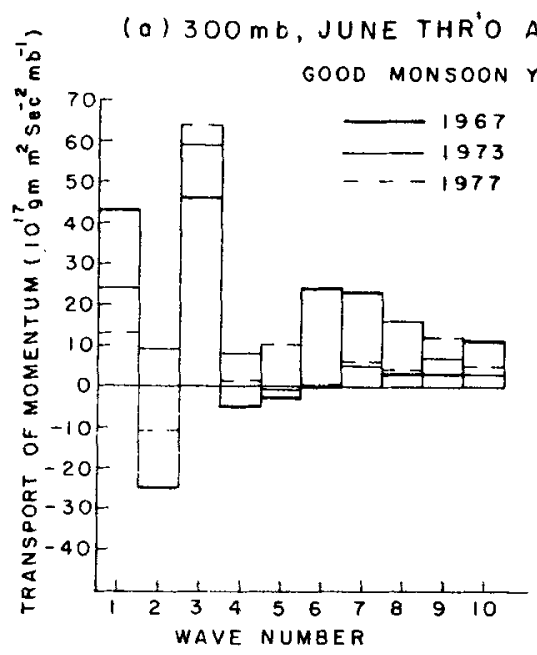

(b) $300 \mathrm{mb}$, JUNE THR'O AUG. BAD MONSOON YEARS

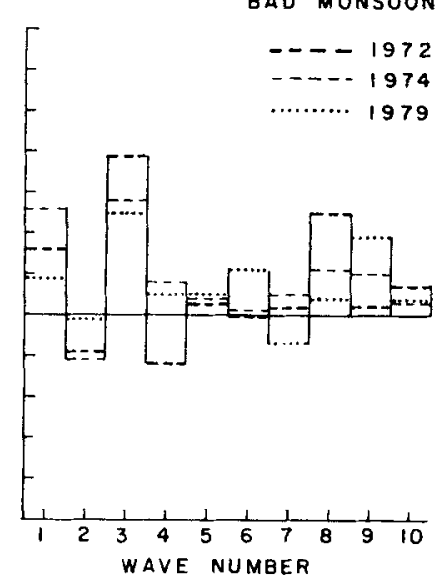

Figure 1. Meridional transport of momentum across $30^{\circ} \mathrm{N}$ at $300 \mathrm{mb}$ level in wave number domain during the period June through August in (a) good monsoon years and (b) bad monsoon years.

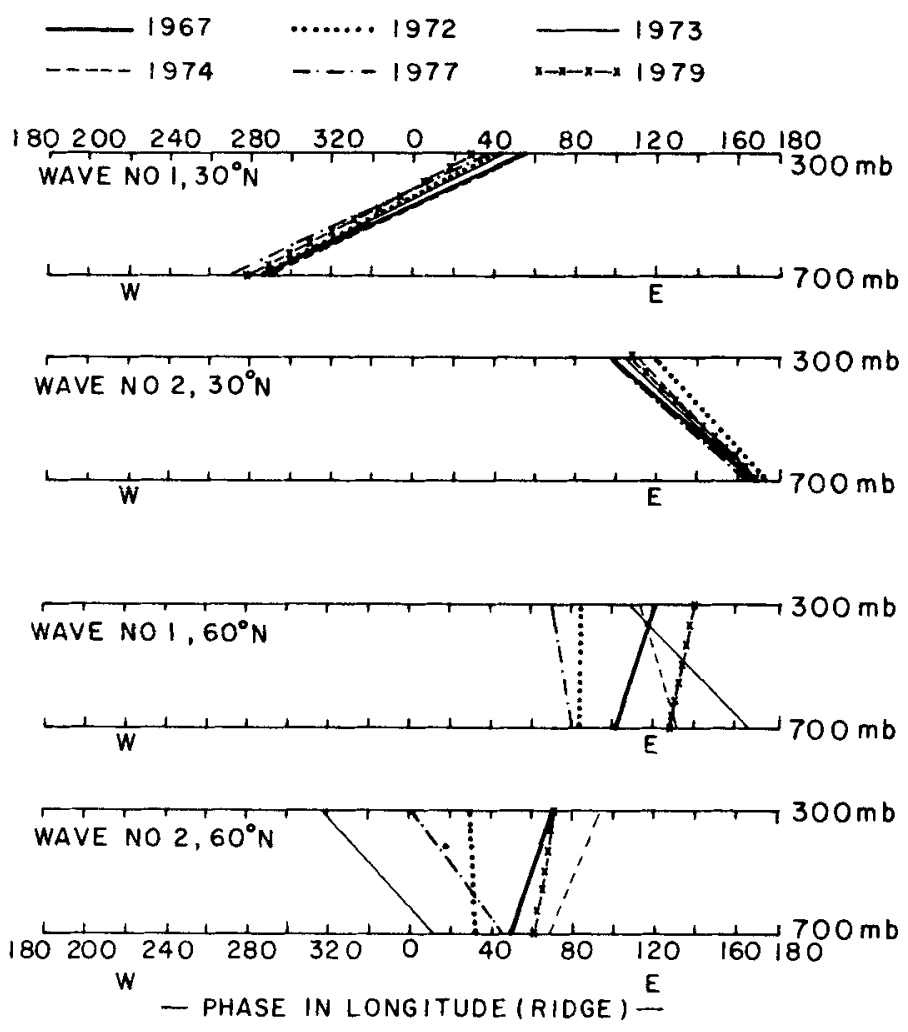

Figure 2. Vertical tilt for waves 1 and 2 at $30^{\circ} \mathrm{N}$ and $60^{\circ} \mathrm{N}$ during July month. 

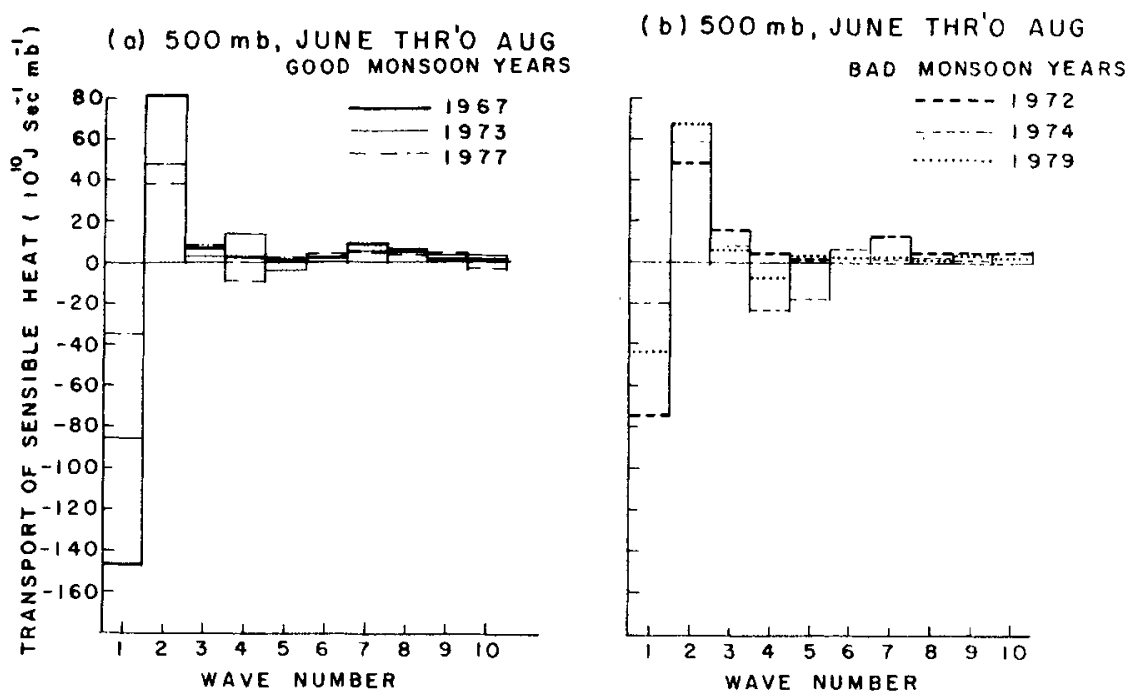

Figure 3. Meridional transport of sensible heat across $30^{\circ} \mathrm{N}$ at $500 \mathrm{mb}$ level in wave number domain during the period June through August in (a) good monsoon years and (b) bad monsoon years.

contrast in these years. At high latitudes, the transport is small. The contribution to sensible heat by short waves is small.

It is noticed that the vertical tilt for wave 1 at $30^{\circ} \mathrm{N}$ is eastward in monsoon months and contributes to southward transport during the period $\mathrm{J}$-A in all these years (figures 2 and 3). It is larger in good monsoon years than in bad monsoon years. Wave 2 tilts westward in vertical and transports sensible heat northward. Waves 1 and 2 contribute the most (figure 3). Waves 3 to 10 contribute to northward transport.

\subsection{Divergence of momentum and of sensible heat}

Table 4 gives the divergence of momentum and of sensible heat during the period J-A. In good monsoon years, there is larger divergence of momentum in subtropics and large convergence of momentum in mid-latitudes during $\mathrm{J}$-A (table 4a). Our results are qualitatively in fair agreement with the results obtained for the year 1970 by Unni Nayar and Murakami (1978). Due to large convergence of momentum in mid-latitudes, the zonal westerlies in mid-latitudes will be stronger in good monsoon years and weaker in bad monsoon years. During weak monsoon activity, zonal westerly flow becomes of low zonal index and blocking high as per findings of many authors (Ramaswamy 1958, 1962; Ramamurthy 1969; Kanamitsu and Krishnamurti 1978). This can be understood through the following mechanism for wave zonal mean flow exchange described by the term

$$
C\left(K_{z}, K_{E}\right)=[\bar{u}](\partial / \partial y)\left[\bar{u}^{*} \bar{v}^{*}\right]
$$

Further, this can be supported by the earlier results (table 2 of Awade et al 1982), where standing eddies supply more energy to zonal mean flow during good monsoon years. 
Table 4a. Divergence of momentum at $300 \mathrm{mb}$ level during the period June through August

\begin{tabular}{|c|c|c|c|c|c|c|c|}
\hline \multirow[b]{2}{*}{ Region } & \multirow{2}{*}{$\begin{array}{c}\text { Latitudinal } \\
\text { belt }\end{array}$} & \multicolumn{3}{|c|}{ Good monsoon years } & \multicolumn{3}{|c|}{ Bad monsoon years } \\
\hline & & 1967 & 1973 & 1977 & 1972 & 1974 & 1979 \\
\hline Subtropics & $20-30^{\circ} \mathrm{N}$ & 90 & 116 & 69 & 39 & 40 & 28 \\
\hline Mid-latitudes & $30-50^{\circ} \mathrm{N}$ & -81 & -120 & -95 & -58 & -18 & -87 \\
\hline
\end{tabular}

Unit: $10^{17} \mathrm{gm} \mathrm{m}^{2} \mathrm{sec}^{-2} \mathrm{mb}^{-1}$

Table 4b. Divergence of sensible heat at $500 \mathrm{mb}$ level during the period June through August

\begin{tabular}{|c|c|c|c|c|c|c|c|}
\hline \multirow[b]{2}{*}{ Region } & \multirow{2}{*}{$\begin{array}{c}\text { Latitudinal } \\
\text { belt }\end{array}$} & \multicolumn{3}{|c|}{ Good monsoon years } & \multicolumn{3}{|c|}{ Bad monsoon years } \\
\hline & & 1967 & 1973 & 1977 & 1972 & 1974 & 1979 \\
\hline $\begin{array}{l}\text { Subtropics } \\
\text { Mid-latitudes }\end{array}$ & $\begin{array}{l}20-30^{\circ} \mathrm{N} \\
30-50^{\circ} \mathrm{N}\end{array}$ & $\begin{array}{l}22 \\
44\end{array}$ & $\begin{array}{r}27 \\
7\end{array}$ & $\begin{array}{r}55 \\
-5\end{array}$ & $\begin{array}{r}57 \\
-15\end{array}$ & $\begin{array}{r}53 \\
-50\end{array}$ & $\begin{array}{r}59 \\
-17\end{array}$ \\
\hline
\end{tabular}

Unit: $10^{10} \mathrm{j} \mathrm{sec}^{-1} \mathrm{mb}^{-1}$

The mid-latitude westerlies therefore, will be stronger in good monsoon years when compared to bad monsoon years.

In bad monsoon years, there is large divergence of sensible heat in subtropics and large convergence in mid-latitudes during J-A (table $4 \mathrm{~b}$ ).

The bad monsoon activity is thus associated with greater divergence of sensible heat and consequently weakening of existing meridional temperature gradient in the tropics in summer. This causes abnormally low temperatures in the tropics in the bad monsoon years. Verma (1980) found that the upper troposphere over north India is cooler than normal during bad monsoon years. There prevailed abnormally low temperature over southern part of USSR, Iran, Afghanistan and north India in 1972 (Keshavamurthy and Awade 1974). The weakening of the temperature gradient in the tropics is manifested in less northward transport of momentum in bad monsoon.

\subsection{The contrast of transport of momentum and of sensible heat during pre-monsoon months (April and May)}

Table 5 gives the transport of momentum and of sensible heat across $30^{\circ} \mathrm{N}$ during April and May (premonsoon months) in these years to see whether there are any signatures in these quantities during April and May (before the commencement of the summer monsoon) which foretell the performance of monsoon rains.

It is observed that during April and May, the northward transport of momentum across $30^{\circ} \mathrm{N}$ at $300 \mathrm{mb}$ level is larger in good monsoon than in bad monsoon years except in the year 1977. The year 1977 does not fit into the pattern. The northward transport of sensible heat at $500 \mathrm{mb}$ level is larger in bad monsoon years than in good 
Table 5. Transport of momentum and of sensible heat across $30^{\circ} \mathrm{N}$ during April and May

\begin{tabular}{|c|c|c|c|c|c|c|c|}
\hline & \multirow[b]{2}{*}{ Level } & \multicolumn{3}{|c|}{ Good monsoon years } & \multicolumn{3}{|c|}{ Bad monsoon years } \\
\hline & & 1967 & 1973 & 1977 & 1972 & 1974 & 1979 \\
\hline Momentum & $300 \mathrm{mb}$ & 228 & 245 & 5 & 145 & 155 & -84 \\
\hline Sensible heat & $500 \mathrm{mb}$ & 27 & 10 & 18 & 79 & 57 & 22 \\
\hline
\end{tabular}

Unit: Momentum: $10^{17} \mathrm{gm} \mathrm{m}^{2} \mathrm{sec}^{-2} \mathrm{mb}^{-1}$; Sensible heat: $10^{10} \mathrm{j} \mathrm{sec}^{-1} \mathrm{mb}^{-1}$.
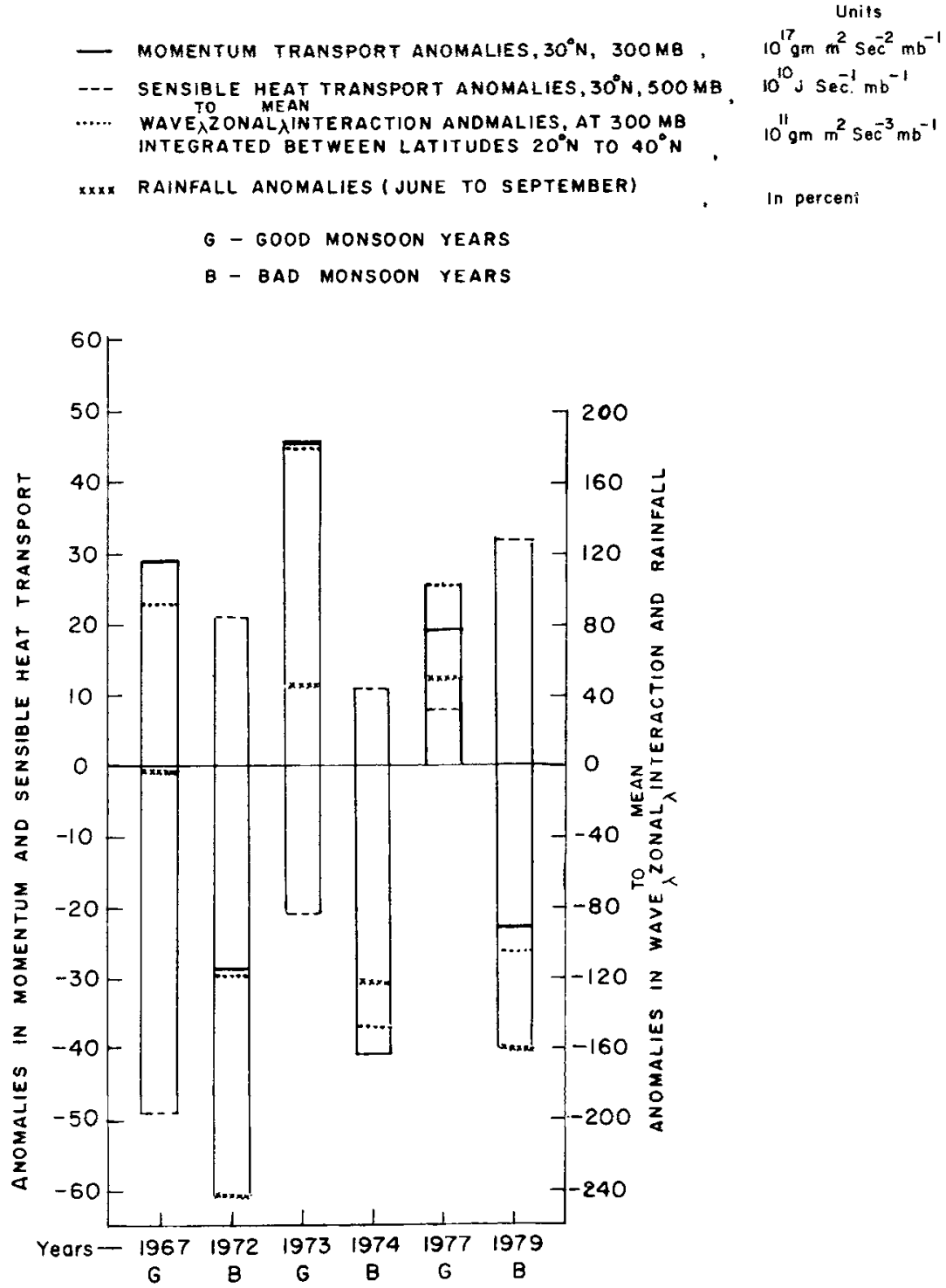

Figure 4. Comparison of anomalies during the period June through August in the transport of momentum, of sensible heat and wave to zonal mean interactions with anomalies in rainfall $(\%)$ in good and bad monsoon years. 
monsoon years. Similar contrast is observed in the earlier section during June through August.

3.5 Comparison of anomalies in the transport of momentum, of sensible heat and wave to zonal mean interactions with anomalies in rainfall.

We have computed the average of six years and obtained the anomalies from these means for each quantity and for each year as shown in figure 4. The anomalies in rainfall are as given in table 1.

It is observed that the positive anomalies of rainfall (i.e. normal or good monsoon year) go with the positive anomalies of transport of momentum and wave to zonal mean flow interactions. However, it goes with the negative anomalies in case of sensible heat flux. In case of bad monsoon years, the anomalies in the rainfall, transports of momentum and wave to zonal mean flow interactions are negative while the anomalies in the sensible heat flux are positive. The authors are aware of the small sample of good and bad monsoon years. However, from the analysis we get a hint that contrast exists in years of good and bad monsoon activity. But we could arrive at convincing results if analysis is repeated for more cases.

\section{Conclusions}

Waves 1 through 3 show contrasting features during years of good and bad monsoon activity and the contrast is significant across $30^{\circ} \mathrm{N}$ at upper troposphere. The northward transport of momentum across $30^{\circ} \mathrm{N}$ is larger in good monsoon years than in bad monsoon years in both pre-monsoon and monsoon months.

In good monsoon years there is large divergence of momentum in sub-tropics while there is large convergence of momentum in mid-latitudes. In bad monsoon years, there is large divergence of sensible heat in subtropics and large convergence in mid-latitudes in mid-troposphere. This leads to a stronger than normal temperature gradient in good monsoon than in bad monsoon years and the westerlies become stronger in midlatitudes and consequently the easterlies in the tropics.

\section{Acknowledgement}

The authors thank Dr Bh V Ramana Murthy, and Shri D R Sikka, for encouragement. They also thank Dr K S Raja Rao for helpful suggestions and Prof G C Asnani of the University of Nairobi for guidance.

\section{References}

Awade S T 1979 Some features of the large-scale circulation during Indian southwest monsoon Ph.D. Thesis, University of Poona

Awade S T, Totagi M Y and Sikka D R 1981 in Proc. Int. Conf. on early results of FGGE and large scale aspects of its monsoon experiments, Geneva, wMO 5-52 to 5-56

Awade S T, Totagi M Y and Bawiskar S M 1982 Pure Appl. Geophys. 120463

Kanamitsu M and Krishnamurti T N 1978 Mon. Weather Rev. 106331 
Keshavamurty R N and Awade S T 1974 Indian J. Meteorol. Geophys. 25257

Lorenz E N 1966 Computations of the balance of angular momentum and poleward transport of heat: Observational studies of the atmospheric general circulation, Scientific Report No. 2, Planetary circulation project, Department of Meteorology, MIT, 32

Pisharoty P R and Desai B N 1956 Indian J. Meteorol. Geophys. 7333

Pisharoty P R and Asnani G C 1958 Proc. monsoons of the world (New Delhi: India Met. Dept.) 112

Ramamurthy K 1969 Some aspects of the 'BREAK' in the Indian southwest monsoon during July and August, India Meteorological Department, Forecasting Manual, Report No. IV-18.3

Raman C R V and Rao Y P 1981 Proc. Int. Conf. early results of FGGE and large scale aspects of its monsoon experiments, Geneva wMo 5-30 to 5-37

Ramaswamy C 1958 Geophysics 6455

Ramaswamy C 1962 Tellus 14337

Unni Nayar N S and Murakami T 1978 Indian J. Meteorol. Hydrol. Geophys. 29170

Verma R K 1980 Mon. Weather Rev. 1081072 